\title{
O EFEITO DO CALOR REFLETIDO NA AVALIAÇÃO DO DESEMPENHO TÉRMICO DE BLOCOS CERÂMICOS UTILIZANDO A TERMOGRAFIA INFRAVERMELHA PASSIVA
}

Rosemary Bom Conselho Sales

Universidade do Estado de Minas Gerais rosebcs@gmail.com

Débora Escárlate Antunes Sátiro Universidade do Estado de Minas Gerais debbieantunes@yahoo.com.br
Solange Andere Pedra

Universidade do Estado de Minas Gerais

solanderepedra@gmail.com

Heloísa Helena Couto

Universidade do Estado de Minas Gerais hhcriar@yahoo.com.br

Maria Teresa Paulino Aguilar

Universidade Federal de Minas Gerais

teresa@ufmg.br

Resumo: Em muitos projetos, as propriedades térmicas de um determinado produto devem ser especificadas na etapa de seleção dos materiais que o compõe. Comumente essas propriedades estão disponíveis para cada material isoladamente, o que dificulta estabelecer as propriedades do produto. Uma das técnicas que possibilita a determinação da condutividade e difusividade térmica de materiais é a termografia infravermelha. Nesta técnica, o calor incide sobre uma das faces do produto e se faz a medição da temperatura na face oposta. Em ensaios realizados em escala reduzida é comum minimizar a interferência do meio ambiente isolando o produto com anteparos. No entanto, o calor que incide sobre ele é refletido por radiação, e pode, devido ao anteparo, provocar a elevação da temperatura no entorno do produto e favorecer a formação de ilhas de calor. Tal efeito poderia prejudicar a determinação do perfil de temperatura do produto. Neste trabalho, a influência desse efeito foi detectada por termografia infravermelha passiva ao se estudar o desempenho térmico de blocos cerâmicos. As amostras foram expostas a radiação solar por 90 minutos, utilizando um anteparo de poliestireno, e tiveram suas temperaturas monitoradas por termografia. Os resultados mostraram que um efeito similar ao da ilha de calor pode ser observado em ambas as faces das amostras, influenciando no perfil de temperatura dos corpos de prova.

Palavras-chave: Ilha de calor, desempenho térmico de materiais, termografia infravermelha.

Abstract: In many projects, the thermal properties of a product must be specified at the stage of selecting its constituents. These properties are commonly available for each material in an isolate manner, making it difficult to establish the product's properties. One of the techniques that 
allow for determining the conductivity and thermal diffusivity of materials is infrared thermography. In this technique, heat falls upon on one of the product sides, and temperature is measured on the opposite face. In tests conducted on reduced-scale models, it is common to minimize interferences from the environment by isolating the product using shields. Nevertheless, the heat that strikes it is reflected by radiation and can, due to the shield, cause the temperature to rise around the product due to the formation of heat islands. Such effect could undermine the determination of the product temperature profile. This work detected the influence of this effect by passive infrared thermography when examining the thermal performance of ceramic blocks. The samples were exposed to solar radiation for 90 minutes using a polystyrene shield and their temperatures were monitored by thermography. Results revealed that the heat island phenomenon could be observed on both sample sizes, thus influencing the temperature profile of the specimens.

Key words: Heat island, thermal performance materials, Infrared thermography.

\section{INTRODUÇÃO}

A escolha dos materiais para estruturação e fechamento do envelope construtivo, na maioria das vezes, está condicionada às questões de custos, regionalidade e estética. Todos esses aspectos vistos em conjunto exercem um forte impacto no desempenho térmico do edifício ao propiciar a reflexão da radiação solar direta para o meio ambiente, sombreamento, resfriamento evaporativo, isolamento térmico, inércia térmica, aquecimento passivo, dentre outros (GONÇALVES e DUARTE 2006). Profissionais que lidam com o projeto, buscam interação com outras áreas do conhecimento, no sentido de buscar soluções para minimizar o impacto ambiental dos edifícios e ao mesmo tempo melhorar as condições de conforto do ambiente construído.

Os blocos cerâmicos são elementos muito utilizados na construção civil para conformação de edifícios. Eles são responsáveis pelo fechamento e contribuem para o conforto térmico interno das construções, e, em determinadas tipologias construtivas, têm função estrutural. De modo geral, ao se especificar materiais construtivos, os aspectos relacionados ao seu desempenho térmico normalmente não são considerados, o que acarreta gastos com climatização artificial na etapa de uso da edificação. Sentir-se confortável é uma das necessidades primárias do ser humano, logo, ao se estabelecer uma relação entre design e conforto, é possível vincular questões subjetivas de conforto aos proporcionados pelos materiais que compõe o fechamento das edificações, uma vez que eles são responsáveis pelo calor absorvido e refletido para o meio ambiente. Assim, etapas de planejamento dos aspectos físicos de uma edificação são importantes, visto que é nesta fase que as informações sobre as características dos materiais, o clima local, as exigências humanas de conforto, dentre outras, podem ser cruzadas e avaliadas buscando uma construção eficiente, do ponto de vista do conforto térmico e da sustentabilidade (FROTA; SHIFFER, 2001; LAMBERTS, 2014). 
A literatura trata das propriedades térmicas dos materiais, contudo, a determinação das propriedades dos produtos e a percepção dos seus efeitos sob o meio ambiente não é simples (ASHBY,2005; CALLISTER, 2006). Estudos mostram que uma das ferramentas para avaliação do desempenho térmico de produtos é a termografia infravermelha. A termografia é uma técnica de inspeção não destrutiva e não invasiva utilizada para medir as características térmicas de superfícies de diferentes tipos de materiais. O método fornece as distribuições de temperatura da superfície dos elementos em estudo de forma não invasiva, mesmo quando grandes gradientes estão envolvidos. (CASTANEDO, 2005). O método de medição por termografia infravermelha, utiliza sensores térmicos para a captação da radiação incidente, sendo necessário um diferencial de temperatura entre o objeto em estudo e o ambiente onde ele está inserido. Tal efeito pode ser conseguido por estímulo externo com aquecimento ou resfriamento artificial do material, nesse caso a técnica é considerada como ativa. Quando não existe nenhum tipo de estímulo a técnica é considerada passiva, sendo natural o gradiente de temperatura existente entre 0 objeto e o meio. A análise pelo método passivo conta com as condições naturais e do seu entorno, sendo o calor do sol um fator determinante (CERDEIRA et al., 2011; KAROGLOU et al., 2011). Os resultados de análises de sistemas passivos são, basicamente, de caráter qualitativo, ou seja, por análise de diferenças em seus padrões de distribuição térmica (MALDAGUE, 2002).

A técnica da termografia tem evoluído muito nos últimos anos o que proporciona significativos ganhos na sua utilização. Ela tem sido utilizada para determinação de propriedades térmicas de diferentes materiais e produtos, mas poucos são os trabalhos sobre materiais utilizados na construção civil. Em alguns desses trabalhos se procura isolar o objeto de estudo das interferências do meio ambiente (SALES, at. al. 2015; SATIRO at. al., 2015; GAMA, at. al. 2013; ALVARENGA at. al., 2012). Barbosa at. al., (2014) utilizam a termografia aliada a modelo matemático, para avaliação da difusividade térmica de componentes planos. Os resultados fornecem um repertório teórico, para o design de materiais, com foco no conforto térmico de edificações. MAXIMO at. al. (2016) avaliam a condutividade térmica e a difusividade térmica, por termografia, em amostras contendo micropartículas de vidro produzidas em laboratório em substituição parcial ao cimento Portland. Os resultados mostram que o resíduo aumentou o tempo da difusão de calor dos compostos e melhorou o desempenho térmico nos materiais. No entanto o calor que incide sobre o material em estudo é refletido por radiação, e pode, devido ao anteparo utilizado para isolar o objeto das interferências do ambiente, provocar a elevação da temperatura do entorno do produto de forma similar ao que acontece quando se formam as ilhas de calor. Nóbrega (2010), define ilha de calor como o aumento da temperatura do ar das cidades em relação às zonas menos urbanizadas e ressalta que o fenômeno normalmente ocorre em conjuntos densos e compactos de edificações. Tal efeito poderia prejudicar a determinação do perfil de temperatura do produto por termografia, como mostrado por Lemos (2011) ao analisar o efeito da espacialidade na intensidade da ilha de calor. O autor mostra que o efeito está diretamente relacionado à morfologia dos centros urbanos, sendo a forma e as características das estruturas que a compõem o que favorece a retenção da radiação solar, diminuição da velocidade dos ventos e dificuldade para dispersão do calor. 
De forma a avaliar a ocorrência desse efeito em ensaios com modelos em escala reduzida, neste trabalho, se analisa o desempenho térmico de blocos cerâmicos, com e sem utilização de anteparos para isolar o objeto de estudo das interferências do meio ambiente, por meio de termografia infravermelha passiva.

\section{MATERIAIS E MÉTODOS}

O efeito de influência do calor refletido na avaliação do desempenho térmico utilizando a termografia infravermelha passiva se iniciou pela confecção de amostras a partir de blocos cerâmicos e argamassas comumente utilizados para fechamento de envoltórias. Simultaneamente foi feita a análise do entorno imediato para levantar as variáveis climáticas no momento do estudo: radiação solar; nebulosidade e ventos. Em seguida as amostras foram submetidas à radiação solar e procedeu-se as medições termográficas. O local dos testes foi uma área externa da Escola de Design.

\subsection{Confecção das amostras}

As amostras foram confeccionadas com tijolos cerâmicos de seis furos, revestidos com três tipos e argamassa. A primeira preparada de forma tradicional conforme recomendação da NBR 7200 (ABNT, 1998): uma parte de cimento Portland CPIV para 8 partes de areia comum lavada. As outras duas argamassas foram confeccionadas com agregado miúdo reciclado cimentício e agregado miúdo reciclado cerâmico. Estas argamassas foram preparadas com uma parte de cimento Portland CPIV, sete partes de agregado reciclado (cimentício ou cerâmico) e duas partes de cal hidratada. Em todas as amostras, a espessura da camada de argamassa aplicada foi de $10 \mathrm{~mm}$, de forma a se evitar microfissuras indesejáveis ao acabamento. Após esse procedimento as amostras permaneceram por um período de 28 dias em local protegido da radiação solar. Transcorrido este tempo, as amostras foram envolvidas nas laterais por uma moldura de lã de vidro (Feltro Masterso, aluminizado). A espessura da lã foi de $25 \mathrm{~mm}$ e a face aluminizada foi posicionada para o exterior. Sobre a lã de vidro foi colocado uma placa de gesso acartonado de $10 \mathrm{~mm}$ de espessura para evitar frestas entre o bloco e a lã de vidro, conforme Figura 1 (a) e (b). Este procedimento teve como objetivo isolar as extremidades dos blocos e impedir o fluxo de calor no sentido ascendente e descendente causados pelos espaços de ar confinados e não ventilados da amostra (FROTA e SHIFFER, 2007).

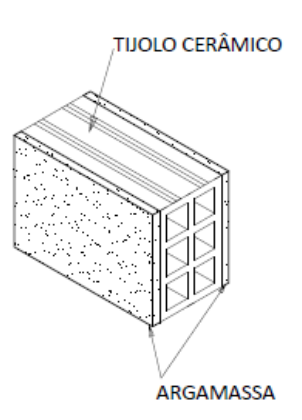

(a) Esquema de montagem da amostra

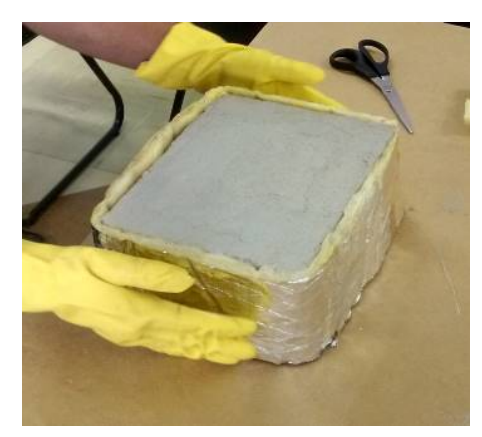

(b) Montagem da amostra

Figura 1 - Preparação das amostras.

Fonte: "Elaborado com base na pesquisa realizada". 


\subsection{Análise do entorno}

A área de estudo corresponde a um recorte urbano no entorno externo e descoberto da Escola de Design, situada no bairro Pampulha cidade Belo Horizonte no Estado Minas Gerais. Para execução dos testes, foi feito uma análise do entorno imediato, para verificar a incidência de insolação e as características do clima da região. Tal análise foi realizada para definir o melhor posicionamento do modelo, uma vez que estas variáveis afetam as trocas térmicas entre as amostras e o ambiente. Foram considerados: o microclima do entorno da Escola de Design, o mesoclima para região norte do bairro Pampulha, e o macro clima da região metropolitana. As orientações de insolação das fachadas do prédio existente, foi analisada por cartas solares.

Para as medições das variáveis foi utilizado um termo-anemômetro digital modelo TAN 100 da marca Incoterm, com faixa de medição de temperatura de $-30^{\circ} \mathrm{C}$ a $60^{\circ} \mathrm{C}$, velocidade do ar de $0,4 \mathrm{~m} / \mathrm{s}$ a $30 \mathrm{~m} / \mathrm{s}$ (ou $1,44 \mathrm{~km} / \mathrm{h}$ a $108 \mathrm{~km} / \mathrm{h}$ ) com precisão \pm $3 \%$ na leitura de medição, calibrado pelo fabricante.

\subsection{Testes de termografia infravermelha passiva}

Inicialmente, para os testes de termografia infravermelha passiva as amostras permanecem à sombra para aclimatar. Em seguida elas foram posicionadas sobre um anteparo (suporte) construído de lâminas de poliestireno (isopor) segundo uma geometria que minimizasse as interferências do meio ambiente nas medições (Figura 2a). O suporte foi colocado sobre uma base de aço e posicionadas as amostras: a amostra com argamassa tradicional foi posicionada a direita das demais e a de agregado miúdo reciclado cimentício à esquerda. Em uma terceira etapa foram retiradas as placas de isopor laterais e traseira e, após 15 minutos, foram realizadas novas medições (Figura 2b).

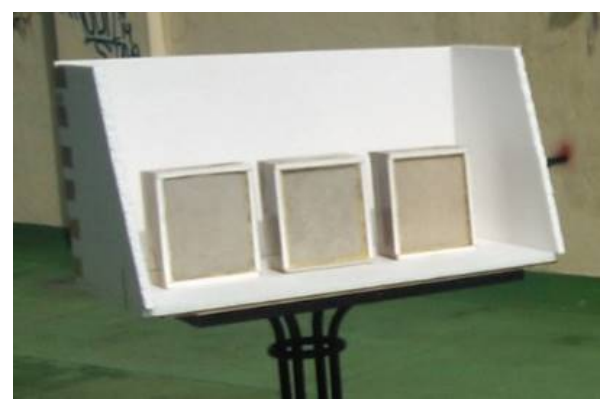

(a)

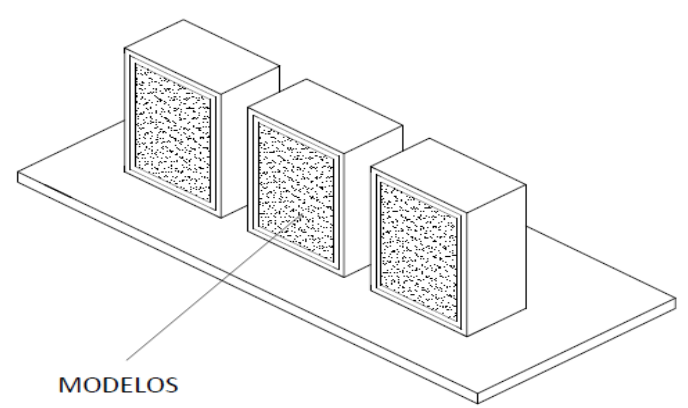

(b)

Figura 2 - Amostras com e sem o anteparo de isopor.

Fonte: "Elaborado com base na pesquisa realizada".

Nas medições de temperatura, utilizou-se uma câmera de infravermelho Thermacam, modelo P640 da Flir Systems. A câmera trabalha com uma faixa de temperatura que varia entre -40 a $500^{\circ} \mathrm{C}$, e precisão de $\pm 2 \%$ da leitura de medição. 0 equipamento foi posicionado a 1,50m de distância das amostras. Foram realizadas 14 medições. Inicialmente foi feita uma medição em cada lado dos blocos (frente e verso), antes dos mesmos serem expostos a insolação direta. Tal procedimento teve como finalidade verificar se os blocos se encontravam em equilíbrio térmico com o ambiente. Após a primeira medição (10 horas), as amostras foram expostas à radiação solar. Procedeu-se a mais 12 medições que aconteceram a cada 15 minutos, sendo 
que, após 75 minutos, foram retidas as placas laterais e posterior do suporte de isopor e realizadas as últimas medições. As imagens captadas foram analisadas pelos softwares QuickReport 1,2 SP1 da Flir Systems.

\section{RESULTADOS}

\subsection{Análise do entorno}

A circulação dos ventos parte em sentido horizontal, da direção nordeste (ENE) e sudeste (SSE) para sudoeste (WSW), devido à topografia local, ao posicionamento e a altimetria das construções locais. Dessa forma, definiu-se como local de estudo o sentido da fachada voltada para a avenida Antônio Carlos, orientada a ENE $\left( \pm 20^{\circ} \mathrm{C}\right)$. A observação e registro da insolação e das sombras projetadas pela edificação definiram o deslocamento do modelo conforme o movimento do sol, para que o mesmo recebesse insolação frontal e uniforme durante todo tempo de testes, conforme demostrado nas imagens da Figuras 3.
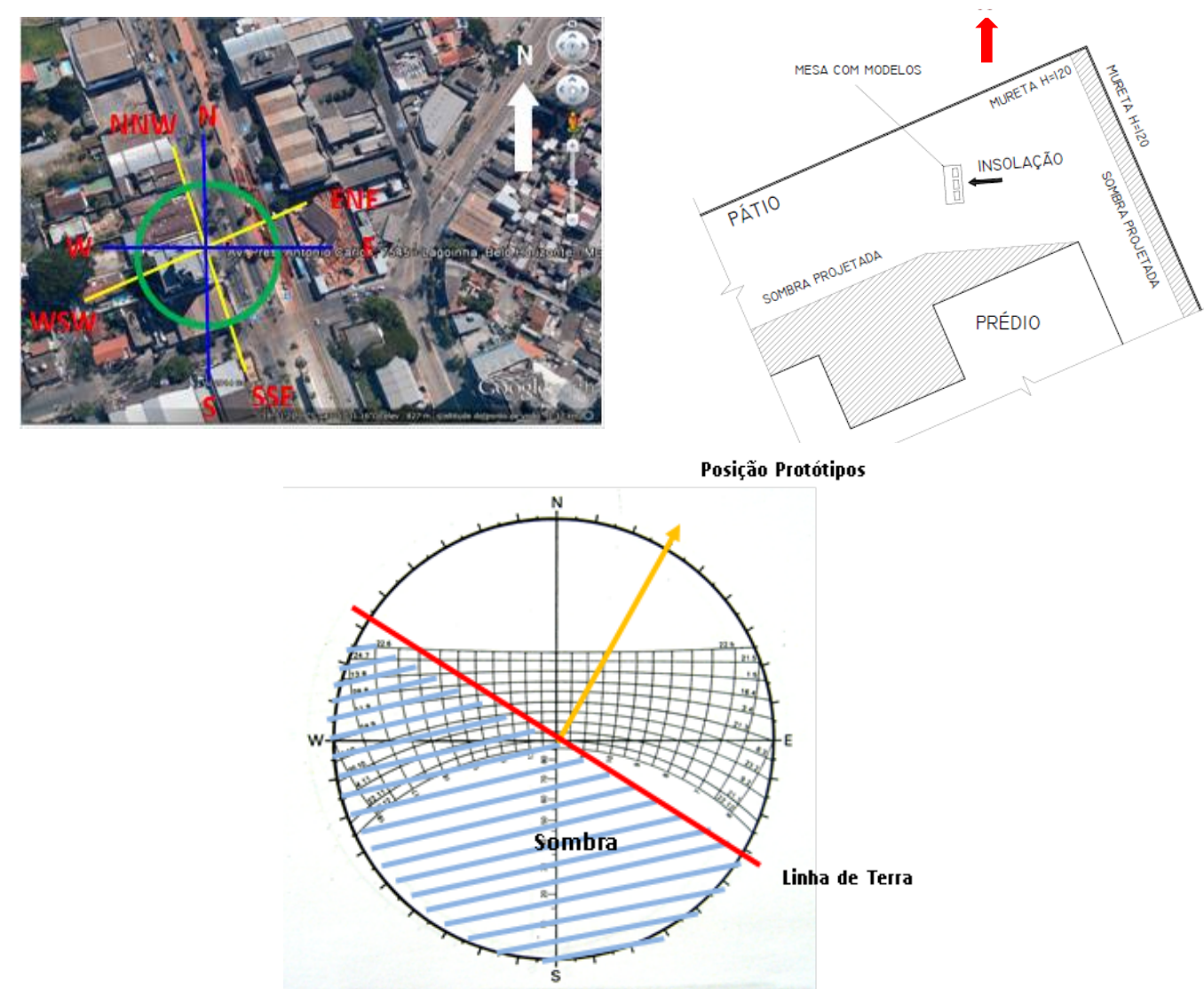

Figura 3 - Posicionamento da edificação, da amostra e carta solar de Belo Horizonte 20 C sul e posição com a normal a $30^{\circ} \mathrm{C}$ NNE.

Fonte: "Elaborado com base na pesquisa realizada".

Devido à poluição e à baixa umidade relativa do ar, o céu se apresentava no momento dos testes sem nuvens, porém em estado anisotrópico. A estação do ano foi início da primavera (setembro) o clima se encontrava seco, umidade relativa em torno de $30 \%$, temperatura média, no momento das medições, encontrava-se a $28.5^{\circ} \mathrm{C}$, com amplitude $16^{\circ} \mathrm{C}$, velocidade média dos ventos de $1.5 \mathrm{~m} / \mathrm{s}$ e com variação de $1.2 \mathrm{~m} / \mathrm{s}$ (mínima) a $1.7 \mathrm{~m} / \mathrm{s}$ (máxima). 


\subsection{Testes de termografia infravermelha}

Nas Figuras 4 e 5 são apresentados o conjunto de termogramas realizados antes e após a insolação das amostras. Adotou-se como área de medida a parte central do modelo (local de menor variação da temperatura). A escala de cores na lateral direita dos termogramas mostra as diferenças de temperaturas, sendo as mais frias na parte inferior (cor preta) e as mais quentes na parte superior (cor branca).

Os resultados obtidos para os blocos antes da insolação (Figura 4) mostram que os mesmos se encontravam à temperatura de $30^{\circ} \mathrm{C} \pm 2^{\circ} \mathrm{C}$. De acordo com $\mathrm{O}$ termograma (frente e verso) a temperatura ambiente variou de 31,2 a $26.2^{\circ} \mathrm{C}$, o que indicaria estarem os blocos em equilíbrio térmico com o ambiente. Não foi observada a influência do tipo de argamassa nestas medições.
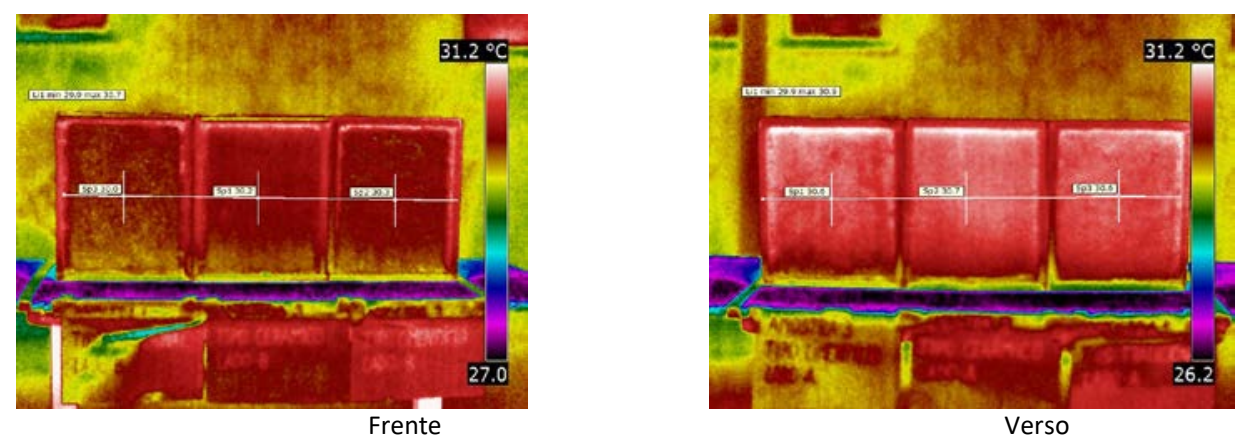

Figura 4 - Termograma dos blocos revestidos com argamassas antes da insolação. Fonte: "Elaborado com base na pesquisa realizada".

A Figura 5 apresenta o conjunto de termogramas das 12 medições das amostras sob insolação (frente e verso) sendo 10 utilizando o anteparo de isopor de poliestireno nas laterais e ao fundo e mais 2 medições sem o anteparo.

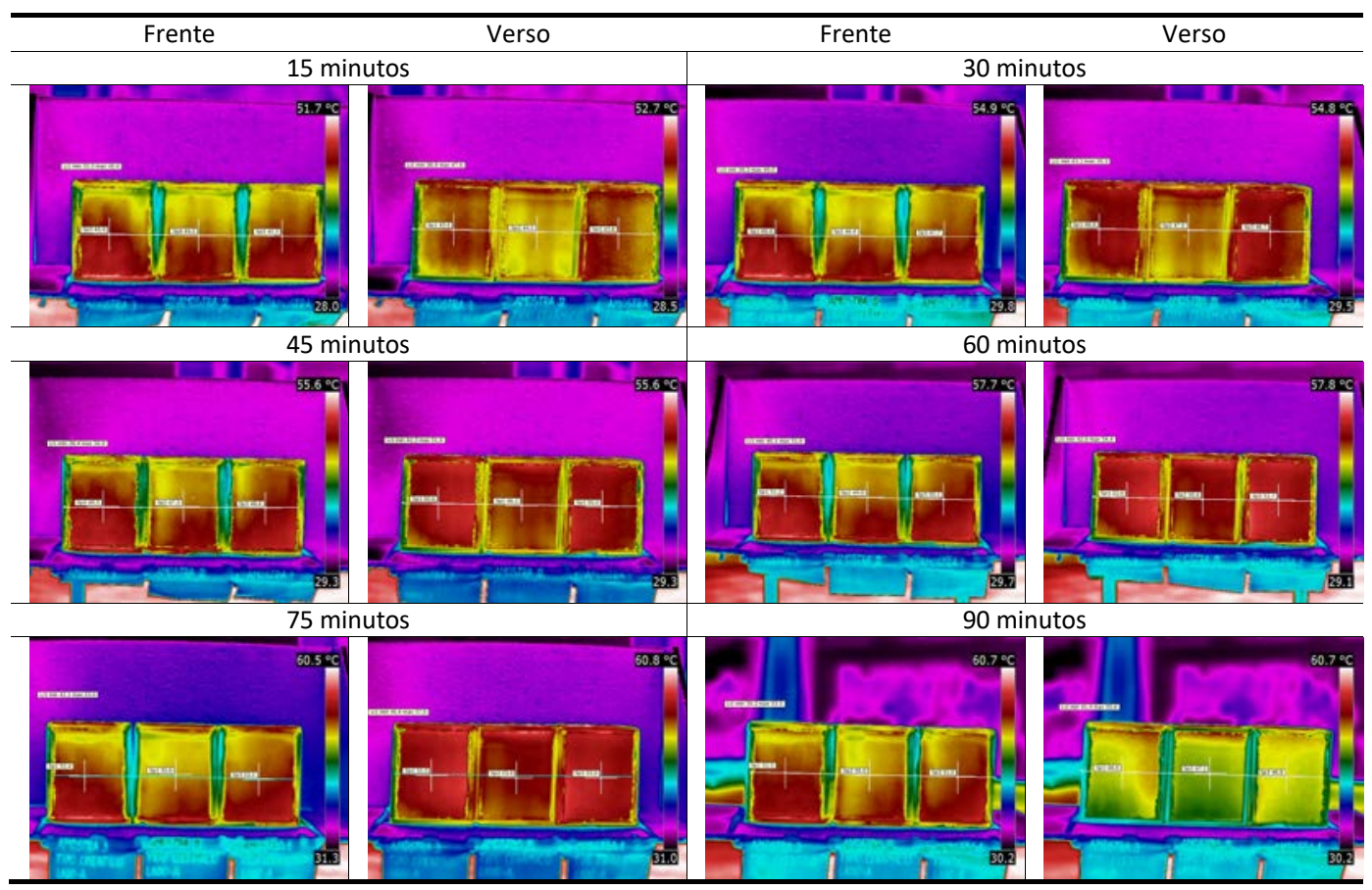

Figura 5 - Termograma das medições no período de insolação com e sem anteparo de isopor. Fonte: "Elaborado com base na pesquisa realizada". 
A Tabela 1 mostra os valores das medições realizadas durante os 90 minutos de teste. Os resultados mostram que as amostras após receber insolação de 75 minutos apresentaram, na face frontal, um aumento de $17,7^{\circ} \mathrm{C}$, enquanto o verso teve um aumento de $21,3^{\circ} \mathrm{C}$, ou seja, a parte posterior das amostras apresentou uma temperatura $3,6^{\circ} \mathrm{C}$ maior que a face na qual incidia os raios solares. A diferença de temperatura entre cada medição, foi de aproximadamente $2,5^{\circ} \mathrm{C}$, indicando ter sido $\mathrm{o}$ aquecimento uniforme.

Após a retirada das placas de poliestireno, e decorridos mais 15 minutos de insolação, constata-se um abaixamento da temperatura em ambas as faces do modelo, sendo este abaixamento maior no verso das amostras: $1,7^{\circ} \mathrm{C}$ na face frontal e $5,7^{\circ} \mathrm{C}$ no verso. Não foi identificado diferenças significativas no comportamento dos blocos revestidos com diferentes tipos de argamassas.

A maior temperatura observada na parte posterior dos blocos, quando utilizadas as chapas de poliestireno nas laterais e traseiras, e a menor temperatura observada na parte posterior quando retiradas essas placas mostram claramente a influência do calor refletido pelo anteparo. Conforme aferido pelo termoanemômetro, no momento, a velocidade dos ventos se encontrava a $1.7 \mathrm{~m} / \mathrm{s}$ e a temperatura atmosférica a $31.6^{\circ} \mathrm{C}$, ou seja, mais baixa que a temperatura das faces do modelo (frente $48,0^{\circ} \mathrm{C}$ e verso $51,7^{\circ} \mathrm{C}$ ). Tais fatores podem ter favorecido a rápida dissipação de calor para o ambiente após a retirada do suporte de isopor. Conforme descrito por Roriz (2008), o ar confinado em espaços pequenos permanece praticamente imóvel, sendo sua condutividade muito baixa, e as trocas térmicas por convecção e por condução podem ser mínimas se o fluxo térmico ocorre apenas por radiação entre as superfícies que formam uma câmara de ar quente.

Tabela 1 - Valores das medições durante o período de insolação de 90 minutos

\begin{tabular}{|c|c|c|c|c|c|c|}
\hline \multirow[b]{2}{*}{ Temp. } & \multicolumn{2}{|c|}{ Frente da amostra } & \multicolumn{2}{|c|}{ Verso da amostra } & \multirow{2}{*}{$\begin{array}{c}\text { Tempo } \\
\text { (minutos) }\end{array}$} & \multirow{2}{*}{$\begin{array}{c}\text { Diferença } \\
\text { entre faces } \\
\left({ }^{\circ} \mathrm{C}\right)\end{array}$} \\
\hline & $\begin{array}{c}\text { Valores } \\
\left({ }^{\circ} \mathrm{C}\right)\end{array}$ & $\begin{array}{c}\text { Média } \\
\left({ }^{\circ} \mathrm{C}\right)\end{array}$ & $\begin{array}{c}\text { Valores } \\
\left({ }^{\circ} \mathrm{C}\right)\end{array}$ & $\begin{array}{c}\text { Média } \\
\left({ }^{\circ} \mathrm{C}\right)\end{array}$ & & \\
\hline Mínima & 29,9 & \multirow{2}{*}{30,3} & 29,9 & \multirow{2}{*}{30,4} & \multirow{2}{*}{ Inicial } & \multirow{2}{*}{0,1} \\
\hline Máxima & 30,7 & & 30,9 & & & \\
\hline Mínima & 33,3 & \multirow{2}{*}{39,8} & 38,9 & \multirow{2}{*}{43,2} & \multirow{2}{*}{15} & \multirow{2}{*}{3,4} \\
\hline Máxima & 46,4 & & 47,6 & & & \\
\hline Mínima & 39,3 & \multirow{2}{*}{44,6} & 43,1 & \multirow{2}{*}{46,7} & \multirow{2}{*}{30} & \multirow{2}{*}{2,1} \\
\hline Máxima & 49,9 & & 50,3 & & & \\
\hline Mínima & 38,4 & \multirow{2}{*}{44,2} & 42,3 & \multirow{2}{*}{47,1} & \multirow{2}{*}{45} & \multirow{2}{*}{2,9} \\
\hline Máxima & 50,0 & & 51,9 & & & \\
\hline Mínima & 40,1 & \multirow{2}{*}{45,8} & 42,0 & \multirow{2}{*}{48,2} & \multirow{2}{*}{60} & \multirow{2}{*}{2,4} \\
\hline Máxima & 51,6 & & 54,4 & & & \\
\hline Mínima & 42,1 & \multirow{2}{*}{48,0} & 46,4 & \multirow{2}{*}{51,7} & \multirow{2}{*}{75} & \multirow{2}{*}{2,2} \\
\hline Máxima & 53,9 & & 57,0 & & & \\
\hline Aqueci & to total & 17,7 & & 21,3 & & \\
\hline \multicolumn{7}{|c|}{ Medição sem anteparo de isopor (após mais 15 minutos de insolação) } \\
\hline Mínima & 39,2 & \multirow{2}{*}{46,3} & 41,4 & \multirow{2}{*}{46,0} & \multirow{2}{*}{90} & \multirow{2}{*}{0,3} \\
\hline Máxima & 53,5 & & 50,6 & & & \\
\hline \multicolumn{2}{|c|}{ Aquecimento } & 16,0 & & \multicolumn{3}{|l|}{15,6} \\
\hline Abaixan & Temp. & 1,7 & & 5,7 & & \\
\hline
\end{tabular}

O anteparo de isopor provocou o efeito de concentração de calor nos experimentos, uma vez que espaços de ar não ventilados entre duas lâminas paralelas, apresentam resistência térmica em função da sua espessura, do fluxo térmico e da emissividade das superfícies. Considerando que uma parede de maior densidade, 
separando o ambiente exterior do interior, com a temperatura interna menor que a temperatura externa, o sentido do fluxo será do exterior para o interior. Quando a temperatura interna se iguala à externa, o fluxo será interrompido e voltará a ocorrer de forma contrária (Roriz, 2008).

Uma justificativa para o resultado encontrado estaria no fato de que a ilha de calor formada, antes que pudesse se dispersar o calor por convecção para o entorno, teria uma parcela se deslocado novamente para face da amostra (verso) e absorvida por radiação superficial, formando um fluxo térmico contrário, conduzindo para o interior da amostra o calor em direção à face frontal e dissipando-se por radiação superficial para o ambiente (Figura 6).

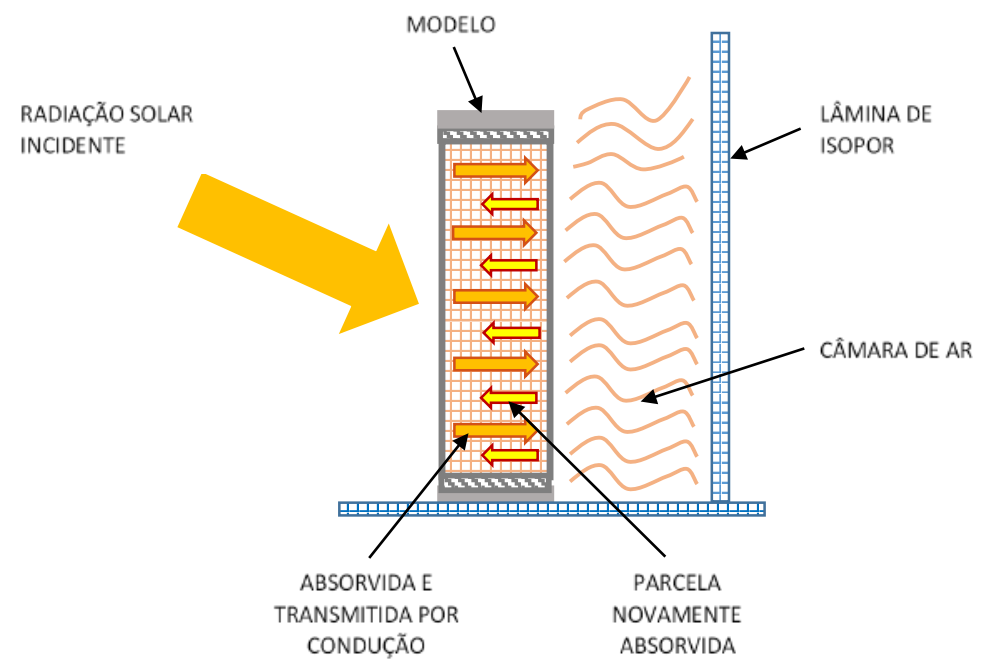

Figura 6 - Esquema da formação de concentração de calor. Fonte: "Elaborado com base na pesquisa realizada".

\section{CONCLUSÃO}

Na determinação do desempenho térmico de produtos utilizando termografia infravermelha passiva deve-se isolar o objeto em estudo do meio, no entanto, tal isolamento não pode permitir a formação de ilhas de calor.

O uso de argamassas tradicionais e com agregado miúdo reciclado cimentício e agregado miúdo reciclado cerâmico, parece não afetar o desempenho térmico dos blocos, com e sem formação a concentração de calor devido à radiação.

\section{AGRADECIMENTOS}

Os autores agradecem à Fundação de Amparo à Pesquisa do Estado de Minas Gerais (FAPEMIG) e ao Conselho Nacional de Desenvolvimento Científico e Tecnológico (CNPq) pelo suporte financeiro a esta pesquisa.

\section{REFERÊNCIAS}

ALVARENGA, Cristiane Bom Conselho Sales; PEDRA, Solange Andere; SALES, Rosemary Bom Conselho. Influência da cor no revestimento cerâmico de fachadas em edificação de alvenaria estrutural, utilizando termografia infravermelha. In: Anais, 10 Congresso 
Brasileiro de Pesquisa e Desenvolvimento em Design, 2012, São Luiz. P\&D Design 2012, 2012. v. 1.

ASHBY, Michael. F. Engineering Materials: An Introduction to Properties, Applications and Design, v.1. Ed. Elsevier: Londres, 2005. 448 p.

ASSOCIAÇÃO BRASILEIRA DE NORMAS TÉCNICAS. NBR 7200. Revestimento de paredes e tetos de argamassas inorgânicas - Procedimento para execução. Rio de Janeiro:

ABNT, 1998, 10p.

SÁTIRO, Débora Escárlate Antunes; COUTO, Heloisa Helena; PEDRA, Solange Andere; SALES, Rosemary Bom Conselho. Estudos de absorção térmica das argamassas de agregados reciclados empregadas em revestimentos de vedações. Anais, IX Encontro Latino-americano de Conforto no Ambiente Construído. ENCAC/ELACAC 15 a 17 de outubro -Campinas, 2015.

BARBOSA, Paula Glória; RODRIGUES, Caroline; ANDRADE, Roberto Márcio; AGUILAR, Maria Teresa Paulino; SALES, Rosemary Bom Conselho. Avaliação da difusividade térmica de blocos cerâmicos maciços utilizando termografia infravermelha. Anais, VIII Congresso Nacional de Engenharia Mecânica, Uberlândia - Minas Gerais, 10 a 15 de agosto de 2014.

CALLISTER, William D. Fundamentos da ciência e engenharia de materiais: uma abordagem integrada. 2. ed. Rio de Janeiro: LTC, 2006.

CASTANEDO, Clemente Ibarra. Quantitative subsurface defect valuation by pulsed phase thermography: Depth retrieval with the phase. Thèse (obtention grade de Philosophiae Doctor Ph.D.) Faculté des Sciences et de Génie Université Laval - Québec. Oct 2005.

CERDEIRA, Fernando et al. Applicability of infrared thermography to the study of the behaviour of stone panels as building envelopes. Energy and Buildings, v. 43, p.18451851, 2011.

FROTA, Anésia Barros; SCHIFFER, Sueli Ramos. Manual do Conforto Térmico. 8. ed., São Paulo: Studio Nobel, 2007. 43 p.

GAMA, Orlando; AYRES, Eliane; PATRÍCIO, Patrícia; SALES, Rosemary Bom Conselho. Avaliação da funcionalidade térmica de compósito polimérico com fibra natural de curauá através da termografia infravermelha. Anais, $12^{\circ}$ Congresso Brasileiro de Polímeros $12^{\circ} \mathrm{CBPol} .2013$.

GONÇALVES, Joana Carla Soares; DUARTE, Denise Helena Silva. Arquitetura sustentável: uma integração entre ambiente, projeto e tecnologia em experiências de pesquisa, prática e ensino. Revista Ambiente Construído, Porto Alegre, v. 6, n. 4, p. 5181 out./dez. 2006. ISSN 1415-8876.

KAROGLOU, Michail et al. Reverse engineering methodology for studying historic buildings coatings: The case study of the Hellenic Parliament neoclassical building. Progress in Organic Coatings, v. 72, p. 202-209, 2011.

LEMOS, Jacqueline de Souza. Espacialização da Ilha de Calor do Aglomerado Urbano da Região metropolitana de Curitiba (AU-RMC) em agosto de 2006 a partir da termografia 
de superfície. Anais, XV Simpósio Brasileiro de Sensoriamento Remoto-SBSR. São José dos Campos: INPE/SELPER, 2011.

MALDAGUE, Xavier P. Introduction to NDT by active infrared thermography. Materials Evaluation, v. 6, p. 1060-1073, 2002.

MAXIMO, Oneida Heiderick; SILVA, Bruno Alves; SALES, Rosemary Bom Conselho; AGUILAR, Maria Teresa Paulino. Avaliação da difusividade térmica de compostos cimentícios confeccionados com micropartículas de resíduo de vidro por meio de termografia infravermelha. Anais, $60^{\circ}$ Congresso brasileiro de cerâmica. Águas de Lindóia, SP, Brasil, 15 a 18 de maio de 2016.

NÓBREGA, Ranyére Silva. Influência da Urbanização sobre o Microclima de Recife e Formação de Ilha de Calor. Revista Brasileira de Geografia Física. 2010, p. 151-156.

RORIZ, Maurício. Conforto e desempenho térmico de edificações. Universidade Federal de São Carlos, Apostila da disciplina. Programa de Pós-Graduação em Construção Civil, 2008.

SALES, Rosemary Bom Conselho; SALES, Fernando Augusto; ALVARENGA, Cristiane Bom Conselho Sales; AGUILAR, Maria Teresa Paulino. Analysis of thermal performance of cementitious compounds using soda-lime glass and infrared thermography. Annals, 3rd International Conference on Mechatronics, Robotics and Automation, ICMRA 2015. 